\title{
Comparação de linguiças defumadas elaboradas com aparas (corte em "V" do filé) de tilápia em relação as de carne de bovino, de suíno e de aves
}

\author{
Comparison of smoked sausages made with tillapia (V-cut) trimmings in relation to those of beef, \\ pork and poultry
}

Comparación de embutidos ahumados elaborados con recortes de tilapia (V-cut) en relación con los de res, cerdo y aves

\section{Resumo}

O presente trabalho teve como objetivo elaborar linguiças defumadas com utilização da matéria prima de diferentes espécies animais (Tilápia, bovino, suíno e aves) e analisar as características químicas, microbiológica e sensorial das mesmas. Foram elaborados quatro tipos de linguiças: sendo uma delas a partir de resíduos de filetagem (corte em "V" do filé) de tilápia, de peito de aves, pernil suína e de carne bovina. Os dados obtidos nas diferentes análises foram submetidos à análise de variância (ANOVA) e aplicado teste de Tukey a 5\% de significância. Foi observada diferença significativa para todos os nutrientes analisados. A linguiça à base de aparas de peixe apresentou valor calórico $(67,14$ $\mathrm{kcal} / 100 \mathrm{~g})$ e baixos teores de lipídios $(4,21 \%)$, proteína $(15,52 \%)$ e altos teores de umidade $(66,84 \%)$ e minerais $(3,80 \%)$, quando comparado com as demais linguiças, porém foi utilizada um resíduo de filetagem e não a parte nobre da carne de peixe (filé). Pela análise sensorial a linguiça à base de aparas de tilápia obteve boa avaliação nos atributos 
cor, aroma, sabor e textura, demonstrando boa aceitação por parte dos consumidores. Todas as linguiças estavam dentro dos padrões exigidos pela legislação, portanto aptas para serem consumidas.

Palavras-chave: Composição química; Resíduo de filetagem; Sustentabilidade.

\begin{abstract}
The present work aimed to elaborate smoked sausages using raw material from different animal species (Tilapia, bovine, swine and poultry) and to analyze their chemical, microbiological and sensory characteristics. Four types of sausages were made: one of them from filleting residues (cut in "V" of the fillet) of tilapia, poultry breast, pork ham and beef. The data obtained in the different analyzes were subjected to analysis of variance (ANOVA) and Tukey's test at 5\% significance was applied. Significant difference was observed for all analyzed nutrients. The sausage based on fish chips had a caloric value $(67.14 \mathrm{kcal} / 100 \mathrm{~g})$ and low levels of lipids $(4.21 \%)$, protein $(15.52 \%)$ and high moisture contents $(66.84 \%)$ and minerals $(3.80 \%)$, when compared to the other sausages, but a filleting residue was used and not the noble part of the fish meat (fillet). Based on the sensory analysis, the tilapia shavings sausage obtained a good evaluation in terms of color, aroma, flavor and texture, showing good acceptance by consumers. All sausages were within the standards required by law, therefore suitable to be consumed.
\end{abstract}

Keywords: Chemical composition; Filleting residue; Sustainability.

\title{
Resumen
}

El presente trabajo tuvo como objetivo la elaboración de embutidos ahumados utilizando materia prima de diferentes especies animales (tilapia, bovino, porcino y aves de corral) y analizar sus características químicas, microbiológicas y sensoriales. Se elaboraron cuatro tipos de embutidos: uno de ellos a partir de los residuos del fileteado (cortado en "V" del filete) de tilapia, pechuga de ave, jamón de cerdo y res. Los datos obtenidos en los diferentes análisis se sometieron a análisis de varianza (ANOVA) y se aplicó la prueba de Tukey al $5 \%$ de significancia. Se observó una diferencia significativa para todos los nutrientes analizados. El embutido a base de chips de pescado tuvo un valor calórico $(67,14 \mathrm{kcal} / 100 \mathrm{~g})$ y bajos niveles de lípidos $(4,21 \%)$, proteínas $(15,52 \%)$ y alto contenido de humedad $(66,84 \%)$ y minerales $(3,80 \%)$, en comparación con el otras salchichas, pero se utilizó un residuo de fileteado y no la parte noble de la carne de pescado (filete). Por análisis sensorial, el chorizo elaborado con virutas de tilapia obtuvo una buena evaluación en los atributos de color, aroma, sabor y textura, mostrando buena aceptación por parte de los consumidores. Todas las salchichas estaban dentro de los estándares exigidos por la ley, por lo que eran aptas para su consumo.

Palabras clave: Composición química; Residuos de fileteado; Sustentabilidad.

\section{Introdução}

A fome mundial vem aumentando a cada ano segundo a Organização das Nações Unidas para a Alimentação e a Agricultura (FAO, 2018), foi registrado pelo terceiro ano, um aumento no número de pessoas passando fome no mundo, que subiu de 815 milhões de indivíduos, em 2016, para quase 821 milhões em 2017, para resolver esse problema, a utilização de subproduto do abatedouro é uma alternativa. A aquicultura é uma atividade promissora com potencial socioeconômico para muitas populações e segundo Sidonio et al. (2012), o Brasil tem recursos propícios para se transformar em um dos maiores produtores de pescado do mundo.

O consumo de pescado no Brasil é de aproximadamente 3,95 kg/hab/ano, está abaixo do mínimo recomendável pela OMS (Organização Mundial de Saúde) (12kg/hab) (FAO, 2018). O baixo consumo de pescado pode ser justificado não só por problemas na distribuição e comercialização do pescado, mas também pela falta do hábito de consumo, gerado, em parte, pela ausência de praticidade no preparo (Bonacina \& Queiroz, 2007). Dentre as espécies nacionais que poderão estimular o consumo de pescado está a tilápia do Nilo que é atualmente a mais cultivada por apresentar alta rusticidade, fácil adaptabilidade, carne nutritiva e de ótima qualidade sensorial (Sá Vieira et al., 2015).

Com todo esse potencial do grande volume de resíduos da pesca e aquicultura, o volume de resíduos gerados pelas indústrias pesqueiras, também é grande após o processamento (Justen et al., 2017). Os referidos resíduos são ricos em compostos orgânicos e inorgânicos, que constituem riscos potenciais de impactos ambientais negativos decorrentes da disposição deste material no meio ambiente, após o aproveitamento do músculo de pescado; porém, os resíduos também são fontes importantes de proteína, vitaminas, minerais e lipídios essenciais para a alimentação humana (Feltes et al., 2010; Bertolin et al., 2011), podendo ser utilizado na forma de produtos elaborados com alta qualidade em função dos nutrientes 
presentes nessa matéria prima e cuidados especiais na logística do abatedouro para melhor aplicação desses resíduos obtidos com a filetagem.

Uma maneira de agregar valor a esses resíduos é a sua utilização em produtos alimentícios, como por exemplo, em linguiça que é um produto muito consumido pela população brasileira e que atende a crescente demanda por alimentos de fácil preparo (Beck et al., 2021).

Conforme o Ministério da Agricultura, Pecuária e Abastecimento (MAPA), entende-se por linguiça o produto industrializado, obtido de carnes de animais de açougue, adicionados ou não de tecidos adiposos, ingredientes, embutido em envoltório natural ou artificial, e submetido ao processo de fabricação: em produtos frescos, produtos secos, curados e/ou maturado, produtos cozidos e outros (Brasil, 2003).

A elaboração de embutidos como por exemplo de linguiças com aparas de tilápia, permite o aproveitamento máximo dos recursos alimentares disponíveis, bem como a utilização de espécies de baixo valor comercial (Monteiro et al., 2018), agregando valor a cadeia produtiva do pescado, assim como auxilia na redução do impacto ambiental dos resíduos gerados e na indução do consumidos em consumir um produto derivado do peixe (Souza et al., 2021a).

Com base na grande importância da aquicultura, principalmente, buscando alternativas para minimizar os impactos da geração de resíduos oriundos do processamento de peixes, o presente trabalho tem como objetivo analisar as características químicas, microbiológica e sensorial de linguiças defumadas elaboradas com carnes de diferentes espécies animais, sendo uma delas a utilização do resíduo da filetagem da tilápia (Oreochromis niloticus), no intuito de agregar valor à cadeia produtiva do peixe, assim como reduzir quantidade de resíduos gerados ao ambiente.

\section{Material e Métodos}

\subsection{Obtenção e preparo das matérias primas utilizadas}

Esta pesquisa é caracterizada como experimental (Pereira et al., 2018). Foram elaborados quatro diferentes tratamentos de linguiças, tratamento 1: linguiça de aparas (Corte em "V" do filé) de filetagem de peixes (Tilápias), tratamento 2: linguiça de peito de aves, tratamento 3: linguiça de pernil suíno e tratamento 4: linguiça com acém bovina. Foi utilizada uma formulação padrão (Tabela 1) onde difere apenas a espécie animal utilizada em cada tratamento.

Para a elaboração da linguiça de peixe foi utilizada aparas de tilápia, proveniente do abatedouro Smart-fish (RolândiaPR). Para tanto, as aparas foram moídas em moedor de carne por 5 vezes, para que minimizasse ao máximo a presença das espinhas presente nesse tipo matéria prima. As carnes dos outros tratamentos foram obtidas em açougues da região de Maringá-PR e moídas em moedor elétrico, seguido da pesagem dos ingredientes (Tabela 1) e a realização da mistura manual para a homogeneização de cada massa com os ingredientes. O embutimento foi efetuado com uso de tripas naturais de suínos (30-32 mm de diâmetro) previamente dessalgadas e com auxílio de funil acoplado ao moedor de carne elétrico. As linguiças foram amarradas com barbantes de algodão manualmente de modo que cada linguiça ficasse com gomos em torno de $6 \mathrm{~cm}$ de comprimento. 
Tabela 1. Formulação de linguiças defumadas de diferentes espécies animais.

\begin{tabular}{lcccc}
\hline \multirow{2}{*}{$\begin{array}{l}\text { Ingredientes } \\
\text { gramas) }\end{array}$} & Peixes & Aves & Suína & Bovina \\
\cline { 2 - 4 } & 1500 & 0 & 0 & 0 \\
\hline Aparas de peixes & 0 & 1500 & 0 & 0 \\
Peito de aves & 0 & 0 & 1500 & 0 \\
Pernil suíno & 0 & 0 & 0 & 1500 \\
Carne acém bovina & 200 & 200 & 200 & 200 \\
Bacon & 36 & 36 & 36 & 36 \\
Sal comum & 70 & 70 & 70 & 70 \\
Condimento para linguiça & 20 & 20 & 20 & 20 \\
Alho desidratado & 5 & 5 & 5 & 5 \\
Cheiro verde & & & & 5 \\
\hline
\end{tabular}

Fonte: Autores.

\subsection{Método e procedimento de defumação utilizado}

As linguiças foram defumadas em defumador de inox tradicional, com geração de fumaça fora da câmara de defumação. $\mathrm{O}$ método de defumação aplicada foi a quente, cuja temperatura utilizada variou de 50 a $80^{\circ} \mathrm{C}$, sendo controlada durante todo o processo. A princípio foi realizada uma secagem parcial, com uma temperatura inicial de $50^{\circ} \mathrm{C}$, por um período de 60 minutos, em estufa de circulação de ar forçada. Em seguida foi adicionada a fumaça obtida pela queima da serragem de eucalipto, por 2 horas, iniciando em $60^{\circ} \mathrm{C}$ e aumentando em torno de $10^{\circ} \mathrm{C}$ por hora de processo de defumação, até atingir $80^{\circ} \mathrm{C}$. Foi utilizado como combustível para produção da fumaça a serragem de eucalipto rosa (Eucalyptus globulus) e, para poder manter a temperatura aplicada no processo de defumação foi utilizado o gás de cozinha. Após o período de duas horas e meia de aplicação de fumaça com a variação de temperatura elas foram retiradas da câmara de defumação. Após esfriamento das linguiças, estas foram embaladas a vácuo e armazenadas sob refrigeração $\left(7 \pm 2{ }^{\circ} \mathrm{C}\right)$.

\subsection{Análise de composição química e valor calórico}

Para a análise de composição química as amostras foram feitas em triplicata, utilizando-se seis linguiças selecionadas aleatoriamente como repetição, por tratamento.

O teor de proteína bruta foi obtido pelo processo semi-micro Kjeldahl, em três etapas distintas (digestão, destilação e titulação), conforme descrito por Silva e Queiroz (2002). A umidade e as cinzas foram realizadas seguindo a metodologia da AOAC (2005). Para o teor de lipídios foi aplicada a metodologia de Bligh e Dyer (1959).

\subsection{Análise microbiológica}

A microbiologia foi realizada no laboratório de Microbiologia e Microscopia de Alimentos, do Departamento de Análises clínicas na Universidade Estadual de Maringá (UEM). A análise microbiológica foi determinada para o número mais provável (NMP) de coliformes a $35^{\circ} \mathrm{C}$ e $40^{\circ} \mathrm{C}$, contagem de Staphylococcus coagulase positiva em unidade formadora de colônia (UFC)/grama. Também foi realizada a análise para Salmonella spp em 25g de amostra, utilizando a metodologia de acordo com APHA (1992).

O protocolo microbiológico seguiu os padrões recomendados pela Resolução RDC nº 12, de 2 de janeiro de 2001, da Agência Nacional de Vigilância Sanitária (Brasil, 2001). 


\subsection{Análise sensorial}

A análise sensorial foi realizada com 80 provadores não treinados, onde receberam uma ficha, um prato com as amostras embaladas em papel alumínio identificadas e um copo de água, para ser consumido entre a avaliação das amostras, como forma de lavar as papilas degustativas, para não haver interferência entre a avaliação das amostras.

Foram fornecidas amostras (cerca de 20g) de cada tratamento, sendo embaladas individualmente em papel alumínio, contendo uma identificação com três números aleatórios. Através de uma ficha de análise sensorial, os provadores avaliaram aspectos como cor, aroma, sabor, textura e impressão global, foi aplicada uma escala hedônica estruturada de 9 pontos, ancorada entre mínimo e máximo: 1 (desgostei extremamente) e 9 (gostei extremamente) (Dutcosky, 2011). As amostras também foram submetidas ao teste de intenção de compra, com escala hedônica de 5 pontos com os extremos 1 (certamente não compraria) e 5 (certamente compraria) (Damásio \& Silva, 1996).

Para realização da análise sensorial os provadores receberam todas as instruções para procederem a avaliação adequadamente. A análise sensorial que envolveu seres humanos foi avaliada e aprovada pelo Comitê de Ética da Universidade Estadual de Maringá (UEM), com Registro CAEE: 71048517.2.0000.0104. O estudo foi realizado conforme os preceitos da Resolução 196/96 do Conselho Nacional de Saúde.

\subsection{Delineamento experimental e análise estatística}

Foi aplicado um delineamento inteiramente casualizado nos dados obtidos nas diferentes análises e submetidos à análise de variância (ANOVA) a 5\% de significância, e em caso de diferenças significativas $(\mathrm{P}<0,05)$ foi aplicado teste de Tukey, com auxílio do programa estatístico SAS Statistical Analysis System (SAS Inst. Inc., Cary, NC, USA, 2010).

\section{Resultados e Discussão}

\subsection{Análise de composição química e valor calórico}

De acordo com os resultados obtidos, verificou-se que houve diferença significativa para todos os nutrientes observados (Tabela 2). O teor de umidade foi significativamente superior para as linguiças de aparas de tilápia (66,84\%) e inferior para as linguiças de carne de aves $(38,30 \%)$. Não foi observado diferença significativa no teor de umidade entre as linguiças suína e a bovina (44,10 e 44,39\%, respectivamente), (Tabela 2).

Segundo Siqueira (2001), o pescado magro apresenta um alto teor de umidade podendo atingir 83\%, ao contrário do pescado gordo que pode apresentar no mínimo 58\%, diante disso, o alto teor de umidade encontrado no presente estudo pode estar associado ao fato de que o músculo de tilápia, que é um peixe magro, pode conter de $60-85 \%$ de umidade (Ogawa \& Maia, 1999; Ordoñez et al., 2005), muito superior ao de aves. Associado a isso, deve-se considerar que as aparas estavam congeladas para proceder o processo de moagem. Esse procedimento deve ocorrer para obtenção de uma uniformidade e melhor quebra das espinhas no procedimento aplicado para minimizar as partículas de espinhas nessa moagem das aparas. Com isso, essa matéria prima contem maior quantidade de água em função do processo de congelamento, contribuindo assim no momento de elaboração da linguiça, e apresentando maior teor de umidade em comparação com as demais linguiças elaboradas, cuja matéria prima não era congelada. 
Tabela 2. Composição química de linguiças defumadas elaboradas com carnes de diferentes espécies animais.

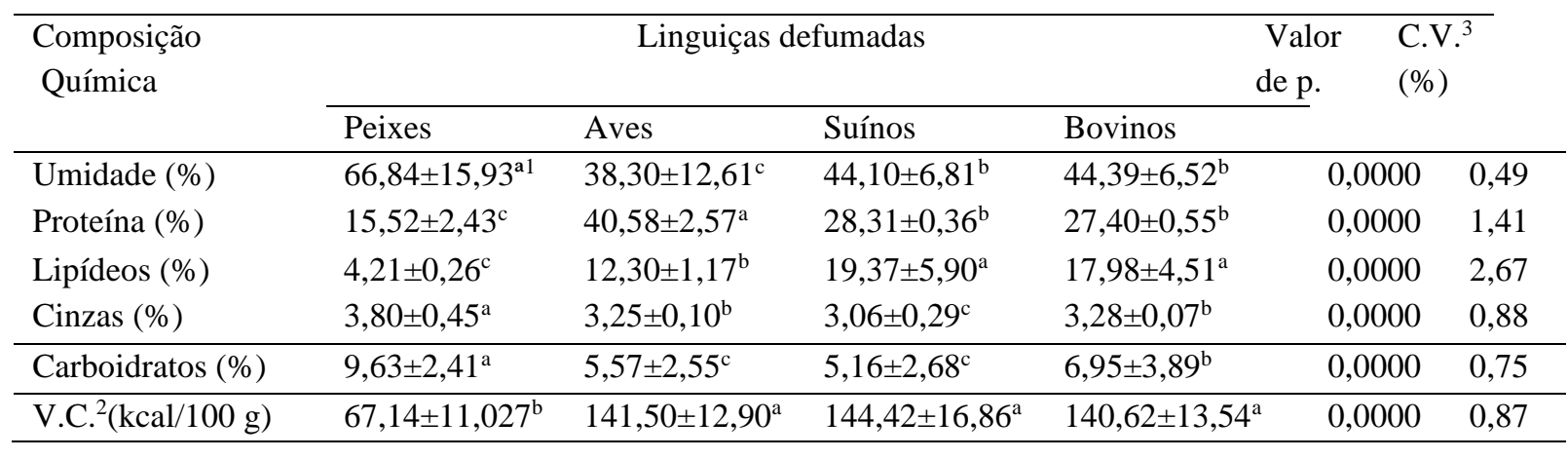

${ }^{1}$ Médias \pm desvio padrão seguidas de letras iguais na mesma linha não diferem pelo teste de Tukey a 5\% de probabilidade. ${ }^{2}$ V.C. $=$ valor calórico, ${ }^{3}$ C.V. $=$ Coeficiente de Variação. Fonte: Autores.

Observou-se que a linguiça, cuja matéria prima foram as aparas de peixe, apresentou um teor de lipídios (gorduras) baixo, quando comparado com as demais linguiças elaboradas com carnes de outras espécies de animais (Tabela 2). Em todos os tratamentos foram adicionados $13,33 \%$ de bacon na elaboração das linguiças, para proporcionar maior maciez e suculência a linguiça, principalmente sabendo-se que para peixes, por apresentar baixo teor de lipídio, se faz necessário esse procedimento (Souza et al., 2021b). Mas o fato da linguiça de aparas de tilápia ter apresentado menor teor, deve-se a espécie animal, pois a tilápia apresenta baixo teor de gordura (Aiura \& Carvalho, 2004) comparado com as demais espécies utilizadas neste trabalho. O teor de lipídios $(4,21 \%)$ da linguiça com aparas de tilápia ficou próximo ao evidenciado por Souza et al., (2004) em filé de tilápia defumado (4,47\%), sendo inferior quando comparados aos encontrado por Vasiliadou et al. (2005) e Franco et al. (2010) para os peixes, dourado $(7,55 \%)$ e matrinxã $(8,09 \%)$ defumados, respectivamente. Contudo, se mostrou superior ao constatado por Gonçalves e Cezarini (2008) para filé de jundiá defumado (2,71\%).

Os valores verificados na composição centesimal do presente trabalho foram semelhantes ao verificado em outros estudos com embutidos à base de peixe, como por Verdi e Souza (2015) que constataram em média 76\% de umidade, 4\% de lipídios e 3\% de cinzas nos diferentes tipos de defumações para linguiça de tilápia. Contudo, divergindo do evidenciado por Vaz (2005), que obteve valores menores no teor de umidade (63-65\%) e proteínas (13-14\%), e superiores em lipídios (4-7\%) e cinzas $(2 \%)$ para linguiça fresca "tipo toscana” de Tilápia.

Pode-se verificar uma grande variação no teor de proteína nas linguiças defumadas deste experimento, onde a linguiça de aves foi a que apresentou o maior percentual médio (40,58\%), seguido pela linguiça suína e bovina com 28,31\% e 27,40\%, respectivamente e o menor teor de proteína foi para a linguiça de tilápia (15,52\%), (Tabela 2). Isto deve-se ao tipo de matéria prima, lembrando-se que nas aparas de tilápia contem elevada quantidade de espinhas que proporciona uma redução proteica e aumento na matéria mineral, assim como o elevado teor de umidade presente nesse tipo de carne.

Sabe-se que a carne do peito de aves apresenta maior teor de proteína comparado com a carne de coxa e menor teor de lipídeos em relação a carne de coxa. Torres et al. (2000) relataram essa variação entre os cortes comerciais de frango. O peito com $20,80 \%$ de proteína e 1,84\% de lipídeos e a coxa com 18,09\% e 9,32\%, respectivamente. No entanto, quanto essa carne é utilizada no processo de defumação, ocorre uma redução no teor de umidade, proporcionando uma grande concentração dos demais nutrientes, como foi o caso da linguiça defumada de peito de aves (frango). Os mesmos autores mencionaram que o peito de frango apresenta 73,81\%de umidade, enquanto a coxa 70,51\%. Se utilizado esse teor de umidade mencionado na carne de peito e comparar com o valor da umidade da linguiça defumada, a perda de umidade teria sido em torno de $54 \%$ e seguindo a mesma avaliação para o teor de proteína, teria concentrado $84,13 \%$ o teor de proteína, com a perda da umidade no processo de defumação. 
O teor de cinzas foi significativamente superior para as linguiças de aparas de tilápia comparada as demais linguiças, sendo as de suínos a que apresentou menores teores deste nutriente. Isto se deve a matéria prima utilizada na elaboração das linguiças, não esquecendo que as de tilápia estavam presentes as espinhas que foram moídas, permanecendo no produto elaborado e este contribuiu grandemente no aumento da matéria mineral (Tabela 2).

Souza et al. (2016) avaliaram linguiças cru e defumada, elaboradas com carne de pirarucu. Os autores relataram que as mesmas apresentaram 70,59\% e 61,93\% de umidade, $19,28 \%$ e 26,43\% de proteína, 2,64\% e 4,07\% de lipídeos e 2,16\% e $3,16 \%$, respectivamente. As linguiças com aparas deste experimento apresentaram menor teor de proteína e maior de umidade e cinzas comparado aos resultados apresentados por Souza et al. (2016). Esta variação nos teores dos nutrientes deve-se a fatores ligados a espécie de peixe, tipo de matéria prima, técnica de elaboração da linguiça com inclusão de diferentes ingredientes. Foram utilizadas aparas congeladas e moídas neste experimento, enquanto de pirarucu os recortes de filetagem que não apresentavam espinhas. Como foi usado aparas do corte em "V" do filé, que contém espinhas, é um fator que favoreceu o aumento na quantidade de cinzas da linguiça de peixe neste experimento. Também as linguiças analisadas neste experimento foram defumadas a quente por um período e temperatura provavelmente diferente ao das defumadas analisadas por Souza et al. (2016), pois os autores não apresentam essas informações da defumação. Mas, tudo indica que o tempo de defumação e/ou a temperatura utilizada tenha sido superior, em função de menores teores de umidade e gordura nas linguiças de pirarucu. As relatadas pelos autores foram cruas e defumadas e apresentaram menores teores de gordura, apesar da inclusão de 5\% de toucinho na linguiça de pirarucu, enquanto neste experimento foi incluído $13,33 \%$ de bacon na elaboração das diferentes linguiças (peixes, aves, suínos e bovinos). Mas, mesmo incluindo esse maior teor de bacon na linguiça com aparas o acréscimo de lipídios nessas linguiças foi muito pequeno. Apesar de isto estar associado a parte utilizada do filé (corte em "V" na parte superior do filé, próximo a cabeça) e a espécie (tilápia), que pode ter contribuído pela pequena variação no teor de lipídeos, nessa comparação com a relatada por Souza et al. (2016).

Oliveira Filho et al. (2017) elaboraram linguiças com carne de filé de tilápia e avaliaram o efeito da defumação tradicional a quente e a líquida. Os autores relataram que o teor de umidade foi de 72,79\% e 71,08\%, 24,25\% e 26,13\% de proteína bruta, $1,16 \%$ e $1,22 \%$ de gordura e de cinzas o teor de 2,58\% e 2,69\%, respectivamente para linguiças defumadas pelo método tradicional a quente e linguiças defumadas por fumaça líquida. A linguiça de aparas de tilápia deste experimento apresentou menor teor de proteína comparada com as demais linguiças de peixes elaboradas pelos pesquisadores mencionados anteriormente (Souza et al., 2016; Oliveira Filho et al., 2017). As linguiças de aparas de tilápia também apresentaram superiores teores de cinzas e de gordura, isto porque nas de aparas tinham as espinhas que elevou o teor de cinzas e nas elaboradas por Oliveira Filho et al. (2017), não incluíram nenhum tipo de gordura na formulação, enquanto Souza et al. (2016) utilizaram 5\% de toucinho de suíno.

Quanto ao valor calórico estimado das linguiças elaboradas neste experimento, as de aparas de tilápia apresentaram significativamente o menor valor $(67,14 \mathrm{kcal} / 100 \mathrm{~g})$ comparado as demais espécies. Isto está relacionado ao maior teor de gordura e proteína presente na carne destas espécies (Tabela 2).

O valor proteico do pescado varia em torno de 15 a $24 \%$, sua carne apresenta bons teores de aminoácidos nas proteínas, e juntamente com a característica de ser um alimento de fácil digestão, é considerado um excelente suprimento nutricional ao organismo (Araújo et al., 2010; Siqueira, 2001). E quando defumado, o pescado apresenta o teor proteico e de lipídios mais elevado quando comparado ao pescado in natura, e isso se dá devido ao processo de desidratação e lixiviação de lipídios do músculo que ocorre durante a defumação, que por sua vez acarreta em uma maior perda de umidade do que proteínas e lipídeos (Sigurgisladottir et al., 2000; Ribeiro, 2000). Contudo, vale ressaltar que a umidade se encontra relacionada diretamente a qualidade, estabilidade e composição do produto, podendo interferir desde seu processamento, estocagem até a embalagem (Izidoro et al., 2008). Diante disso, verifica-se que, entre os embutidos analisados no presente 
estudo, o elaborado a base de pescado se mostra um dos mais perecíveis, devido ao elevado teor de umidade apresentado, que por sua vez, contribui para a proliferação de microrganismos que ocasionam a deterioração do alimento e, dessa forma, reduzindo o seu tempo de prateleira, necessitando de outras formas de conservação para que o embutido defumado mantenha por mais tempo as suas características sensoriais e a sua qualidade nutricional. Entretanto, vale salientar que a linguiça de peixe, foi elaborada com um subproduto de filetagem, que muitas vezes é perdido dentro da linha de processamento do abatedouro ou mal utilizado; e quando utilizado na elaboração da linguiça e ainda defumada, agrega valor comercial ao produto, além de melhor as características sensoriais, em função do processo de defumação, pelos compostos da fumaça que é impregnado na carne.

De acordo com Nunes (1999), por interferir diretamente ao sabor e ao aroma do produto defumado, a gordura se mostra de grande relevância no processamento do embutido a base de peixe. Diante disto, a adição do bacon na produção de linguiça a base de tilápia, funciona como um aditivo no processo de defumação, pois, por ser considerado um peixe magro, a adição de bacon faz com que haja um aumento da taxa de gordura e absorvendo mais os compostos da fumaça, além de resultar na defumação um produto mais suculento, devido à maior dificuldade de perdas da gordura comparado à apenas a umidade (água que é lixiviada no processo de defumação).

\subsection{Análise microbiológica}

De acordo com as análises microbiológicas realizadas, os coliformes a $35{ }^{\circ} \mathrm{C}$ e $45{ }^{\circ} \mathrm{C}$, Staphylococcus coagulase, estavam dentro dos padrões aceitáveis para consumo do produto. A Salmonella spp foi ausente a $25 \mathrm{~g}$ de amostra de linguiça, sendo que sua presença seja qual for a quantidade, o produto deve ser condenado (Tabela 3). Segundo Cardoso e Carvalho (2006), as infecções causadas por bactérias do gênero Salmonella são mundialmente consideradas como as mais importantes causadoras de doenças transmitidas por alimentos. Nos derivados de origem animal a contaminação ocorre mediante a exposição direta, já para a carne isso ocorre no processo de abate (Brasil, 2011).

Tabela 3. Microbiologia de linguiças defumadas elaboradas com carnes de diferentes espécies animais.

\begin{tabular}{|c|c|c|c|c|c|c|c|}
\hline $\begin{array}{l}\text { Linguiças } \\
\text { defumadas }\end{array}$ & $\begin{array}{l}\text { Coliformes } \\
35^{\circ} \mathrm{C}(\mathrm{NMP} / \mathrm{g})\end{array}$ & $\mathrm{a}$ & $\begin{array}{l}\text { Coliformes } \\
45^{\circ} \mathrm{C}(\mathrm{NMP} / \mathrm{g})\end{array}$ & $\mathrm{a}$ & $\begin{array}{l}\text { Staphylococcus } \\
\text { positiva (UFC/g) }\end{array}$ & coagulase & $\begin{array}{l}\text { Salmonella } \\
\text { ssp. } 25 \mathrm{~g}\end{array}$ \\
\hline Peixes & $<3$ & & $<3$ & & $<1 \times 10^{2}$ & & AUSENTE \\
\hline Aves & $<3$ & & $<3$ & & $<1 \times 10^{2}$ & & AUSENTE \\
\hline Suínos & $<3$ & & $<3$ & & $<1 \times 10^{2}$ & & AUSENTE \\
\hline Bovinos & $<3$ & & $<3$ & & $<1 \times 10^{2}$ & & AUSENTE \\
\hline
\end{tabular}

NMP= Número Mais provável. UFC= Unidade Formadora de Colônia. Fonte: Autores.

A ausência de Salmonella spp e os índices aceitáveis de Staphylococcus coagulase evidenciados, demonstram que os procedimentos sanitários foram realizados adequadamente durante o manuseio da matéria prima até a elaboração do produto final, pois quando há uma grande contaminação por essas bactérias, o produto deve ser descartado a fim de evitar intoxicações alimentares.

A maior preocupação era para as linguiças elaboradas com aparas de peixe, pois para o processo de moagem foi necessário seis vezes, em função de minimizar a presença das espinhas e isso poderia proporcionar uma possível contaminação. Mas, isso não ocorreu visto os resultados obtidos (Tabela 3). Apesar de não haver normas específicas para embutidos de pescado na legislação brasileira, há para produtos à base de pescado "in natura", congelados ou refrigerados, onde os limites de contaminação por coliformes é de no máximo de $10^{3} \mathrm{UFC} / \mathrm{g}$, com no máximo de $10^{3} \mathrm{UFC} / \mathrm{g}$ para Staphylococcus coagulase e ausência em 25g de amostra para Salmonella (Brasil, 2001). Deste modo, os embutidos 
elaborados no presente estudo estão dentro dos padrões estabelecidos pela legislação brasileira (Resolução-RDC No12 de 2001), estando aptos ao consumo humano.

Sleder (2015), em seu estudo com linguiça a base de tambaqui (Colossoma macropomum), não detectou microrganismos patogênicos (S. aureus e Salmonella sp.) no período de armazenamento a $4^{\circ} \mathrm{C}$ e não constatou diferença estatística $(p>0,05)$ para coliformes totais no embutido analisado.

\subsection{Análise sensorial}

Não houve diferença significativa para os atributos cor, aroma e para a intenção de compra das linguiças elaboradas, mostrando que a linguiça com aparas de tilápia se iguala as demais para esses atributos, principalmente para a intenção de compra. No entanto, para textura, sabor e impressão global as linguiças de aparas de tilápia apresentaram diferença significativa comparada às demais. As notas dadas pelos provadores para a linguiça de aparas foi significativamente superior para a textura apenas diferindo das linguiças de aves e para o sabor, das linguiças de bovinos. Apenas, quanto a impressão global a de aparas de tilápia, de aves e de bovinos foram as piores (Tabela 4), talvez associado a isso esteja o fato que a carne de peixe, ainda sofre certas restrições comparado a qualquer outra carne, já a de aves por ser menos preterida para embutidos quando comparada as de suínos, assim como a de bovinos menos utilizada também para embutidos.

Tabela 4. Análise sensorial de linguiças defumadas elaboradas com carnes de diferentes espécies animais.

\begin{tabular}{|c|c|c|c|c|c|c|}
\hline \multirow{2}{*}{$\begin{array}{l}\text { Análise } \\
\text { Sensorial }\end{array}$} & \multicolumn{4}{|c|}{ Linguiças defumadas } & \multirow{2}{*}{$\begin{array}{l}\text { Valor de } \\
\text { p. }\end{array}$} & \multirow{2}{*}{$\begin{array}{l}\text { V.C }{ }^{2} \text {. } \\
(\%)\end{array}$} \\
\hline & Peixes & Aves & Suínos & Bovinos & & \\
\hline Cor & $6,58 \pm 0,83$ & $6,27 \pm 1,14$ & $6,36 \pm 1,05$ & $6,43 \pm 0,98$ & 0,9223 & 7,41 \\
\hline Aroma & $7,16 \pm 0,35$ & $7,28 \pm 0,47$ & $6,28 \pm 0,53$ & $6,50 \pm 0,31$ & 0,2071 & 6,60 \\
\hline Textura & $6,56 \pm 0,51^{\mathrm{a} 1}$ & $5,21 \pm 0,84^{\mathrm{b}}$ & $6,35 \pm 0,30^{\mathrm{ab}}$ & $6,07 \pm 0,02^{\mathrm{ab}}$ & 0,0372 & 4,92 \\
\hline Sabor & $6,86 \pm 0,51^{\mathrm{a}}$ & $6,36 \pm 0,01^{\mathrm{a}}$ & $7,14 \pm 0,79^{a}$ & $5,07 \pm 1,28^{\mathrm{b}}$ & 0,0059 & 4,32 \\
\hline Impressão global & $6,66 \pm 0,01^{\mathrm{b}}$ & $6,65 \pm 0,02^{\mathrm{b}}$ & $7,14 \pm 0,47^{\mathrm{a}}$ & $6,22 \pm 0,45^{b}$ & 0,0479 & 3,62 \\
\hline Intenção de compra & $3,62 \pm 0,06$ & $3,15 \pm 0,41$ & $3,86 \pm 0,30$ & $3,63 \pm 0,07$ & 0,1409 & 6,49 \\
\hline
\end{tabular}

${ }^{1}$ Médias \pm desvio padrão seguidas de letras iguais não diferem pelo teste de Tukey a $5 \%$ de probabilidade. ${ }^{2} \mathrm{C} . \mathrm{V} .=$ Coeficiente de Variação. Fonte: Autores.

Com relação a textura, a linguiça à base aparas de peixe obteve maior nota $(6,56)$, não diferindo das de carne de suínos e bovinos, sendo a de aves considerada a com a nota de pior textura $(5,21)$. Lembrando que a linguiças de aparas de tilápia, poderia ser perceptível a presença das espinhas na textura, mas apresentou a maior nota. Na avaliação da impressão geral o embutido a base de carne suína $(7,14)$ se sobressaiu aos demais, porém quando avaliado os atributos de sabor o pior resultado foi significativamente para a linguiça com carne bovina $(5,07)$.

As notas dos atributos variaram de 6,28 a 7,14 para linguiças de suínos e de 6,45 a 7,16 para as linguiças de aparas de peixes. Estas notas segundo Dutcoski (2011) pela escala hedônica de 9 pontos, corresponde a gostei ligeiramente a gostei moderadamente. Em contrapartida para linguiças de bovinos e de aves alguns atributos avaliados receberam notas muito baixas de 5,07 (sabor) e 5,21 (textura), respectivamente. Estas notas, pela escala hedônica de pontos corresponde a nem gostei/ nem desgostei (Dutcoski, 2011). 
Quando avaliado a intenção de compra das linguiças não houve diferença significativa entre elas, cujas notas variaram de 3,15 a 3,86, respectivamente para linguiça de aves e de suínos. Essas notas de acordo com a classificação de Damásio e Silva (1996), corresponde as notas 3 e 4, que talvez comprasse/talvez não comprasse a possivelmente compraria se estivesse no comercio.

De modo geral, observou-se que a linguiça de aparas de tilápia obteve uma boa aceitação por parte dos avaliadores, demonstrando um potencial produto para com o público consumidor de embutidos. Além disso, a boa avaliação na análise sensorial para os quesitos cor, aroma, sabor e textura do embutido com aparas de peixe, pode estar também relacionada ao fato da tilápia possuir quesitos típicos de pescados que são bem aceitos pelos consumidores, como carne branca, de textura firme, sabor delicado e ausência de odor desagradável (Souza, 2002).

Goes et al. (2015) elaboraram snacks extrusados com a adição de diferentes espécies de peixe (tilápia, salmão, atum e sardinha) e na análise sensorial verificaram que em todos os quesitos, o snacks com adição de tilápia foi o mais bem avaliado, recebendo as maiores notas dos provadores, principalmente em função do sabor mais suave da espécie ao produto.

Diante do resultado encontrado, pode-se verificar que a linguiça a base de aparas de tilápia, além de apresentar várias características organolépticas, que no geral foram bem avaliadas pelos provadores, como boa textura, coloração, paladar e aroma agradáveis, demonstraram também um baixo teor de gorduras e calorias, fazendo com que esse embutido seja favorável para ser consumido, mesmo com menor teor de proteína quando comparado as demais linguiças elaboradas e avaliadas neste trabalho.

Isto traz à tecnologia de alimentos uma inovação quanto à proposta ao aproveitamento das aparas do pescado, que além de fornecer alimento proteico de um produto que poderia ser descartado, beneficia o meio ambiente evitando impacto ambiental, assim como agrega valor à cadeia produtiva da tilápia. Além disso, proporciona novas formas de apresentação e aproveitamento dessa matéria prima, tais como produtos prontos ou semiprontos, permitindo agregar praticidade ao seu preparo, o que iria favorecer o consumo de produtos à base de pescado.

\section{Conclusão}

A utilização de diferentes tipos de matéria prima na elaboração de linguiças defumadas demonstrou viabilidade quanto as características nutricional, microbiológica e sensorial.

A linguiça de aparas de tilápia apresentaram várias características organolépticas agradáveis, tais como cor e aroma que não diferiram das linguiças elaboradas com pernil de suíno, peito de frango e carne e bovino, enquanto a de bovina foi considerada a de pior sabor. A linguiças de aparas apresentarem baixo teor de gorduras e calorias, fazendo com que esse embutido seja mais favorável para ser consumido, mesmo apresentando um menor teor de proteína quando comparado as demais linguiças elaboradas e avaliadas neste trabalho. A linguiça e que apresentou a melhor impressão global foi a carne de pernil de suínos. Portanto, a linguiça de aparas de tilápia de um modo geral obteve uma boa aceitação por parte dos avaliadores, demonstrando um potencial produto para com o público consumidor de embutidos, além de agregar valor à cadeia de tilápia e utilizar um resíduo muitas vezes subutilizado ou descartado.

Todas as linguiças estavam dentro dos padrões exigidos pela legislação, portanto aptas para serem consumidas.

Sugere-se a aplicação em outros produtos alimentícios como massas, sopas, etc.

\section{Referências}

APHA. American Public Health Association. (2001). Compendium of methods for the microbiological examination of foods.

AOAC. Association Of Official Analytical Chemists-AOAC. (2005). Official methods of analyses of the association of analytical chemists.

Araújo, D. A. F. V., Paiva, K. M. P., \& Góis, V. A. (2010) Características gerais, processos de deterioração e conservação do pescado. Pubvet, 4, 766-772. 
Aiura, F. S., \& Carvalho, M. R. B. (2004). Composição em ácidos graxos e rendimento de filé de tilápia do Nilo (Oreochromis niloticus) alimentada com dietas contendo tanino. Revista Portuguesa de Ciências Veterinárias, 99, 93-98.

Beck, P., Matiucci, M. A., Monge Neto, A., \& Feihrmann, A. C. (2021). Sodium chloride reduction in fresh sausages using salt encapsulated in carnauba wax. Meat Science, $175,108462$.

Bertolin, T. E., Guarienti, C., Farias, D., Souza, F. T., Gutkoski, L. C., \& Colla, L. M. (2011). Efeito antioxidante da ficocianina em pescado salgado-seco. Ciência e Agrotecnologia. Lavras, 35(4), 751-757.

Bligh, E. G., \& Dyer, W. J. (1959). A rapid method of total lipid extraction and purification. Canadian Journal of Biochemistry and Physiology, 37(8), 911-17. Bonacina, M., \& Queiroz, M. I. (2007). Elaboração de empanado a partir da corvina (Micropogonias furnieri). Food Science and Technology, $27,544-552$.

Brasil. (2001). Ministério da Saúde. Agência Nacional de Vigilância Sanitária. Resolução RDC n. 12, de 02 de janeiro de 2001.Regulamento Técnico sobre os padrões microbiológicos para alimentos.

Brasil. (2003) Ministério da agricultura, pecuária e do abastecimento. Instrução normativa n 62 .

Brasil. (2010). Ministério da Pesca e Aquicultura. Boletim estatístico da pesca e aquicultura. Brasília, 2012. 129p.

Brasil. (2011). Ministério da saúde. Manual técnico de diagnóstico laboratorial de Salmonella spp: diagnóstico do gênero Salmonella. Laboratório de Referência Nacional de Entero infecções Bacterianas, Instituto Adolfo Lutz. - Brasília: Ministério da Saúde.

Cardoso, T. G., \& de Carvalho, V. M. (2006). Toxinfecção alimentar por Salmonella spp* Foodborne disease caused by Salmonella spp. Revista do Instituto de Ciências da Saúde, 24(2), 95-101.

Damásio, M. H., \& Silva, M. A. A. P. (1996). Curso de treinamento em análise sensorial. Apostila Campinas: Fundação Tropical de Tecnologia "André Tosello".

Dutcosky, S. D. (2011). Análise sensorial de alimentos. (3a ed.), Champagnat, p. 426.

FAO. (2018). El estado mundial de la pesca y la aquicultura 2018. Cumplit los objetivos de desarrollo sostenible. Roma.

Feltes, M., Correia, J. F., Beirão, L. H., Block, J. M., Ninow, J. L., \& Spiller, V. R. (2010). Alternativas para a agregação de valor aos resíduos da industrialização de peixe. Revista Brasileira de Engenharia Agrícola e Ambiental, 14(6), 669-677.

Franco, M. L. R. D. S., Viegas, E. M. M., Kronka, S. N., Vidotti, R. M., Assano, M., \& Gasparino, E. (2010). Effects of hot and cold smoking processes on organoleptic properties, yield and composition of matrinxa fillet. Revista Brasileira de Zootecnia, 39, 695-700.

Goes, E. S. R., Souza, M. L. R. de, Campelo, D. A. V., Yoshida, G. M., Xavier, T. O., Moura, L. B. \& Monteiro, A. R. G. (2015). Extruded snacks with the addition of different fish meals. Food Science and Technology, 35(4), 683-689.

Gonçalves, A. A., \& Cezarini, R. C. R. C. R. (2008). Agregando valor ao pescado de água doce: defumação de filés de jundiá (Rhamdia quelen). Revista Brasileira de Engenharia de Pesca, 3(2), 63-79.

Izidoro, D. R., Scheer, A. D. P., Negre, M. F. D. O., Haminiuk, C. W. I., \& Sierakowski, M. R. (2008). Avaliação físico-química, colorimétrica e aceitação sensorial de emulsão estabilizada com polpa de banana verde. Revista do Instituto Adolfo Lutz (Impresso), 67(3), 167-176.

Justen, A. P., Souza, M. L. R., Monteiro, A. R., Mikcha, J. M., Gasparino, E., Delbem, Á. B., Carvalho, M. R. B., \& Del Vesco, A. P. (2017). Preparation of extruded snacks with flavored flour obtained from the carcasses of Nile tilapia: physicochemical, sensory, and microbiological analysis. Journal of Aquatic Food Product Technology, 26, 258-266.

Monteiro, M. L. G., Mársico, E. T., Soares Junior, M. S., Deliza, R., Oliveira, D. C. R., \& Conte-Junior, C. A. (2018). Tilapia-waste flour as a natural nutritional replacer for bread: A consumer perspective. Plos One 13(5), e0196665.

Nunes, M. L. (1999). Defumação. Manual de pesca: ciência e tecnologia. Livraria Varela, 324-335.

Ogawa, M., \& Maia, E. L. (1999). Química do pescado. Ogawa, M.; Maia, EL Manual de pesca: ciência e tecnologia do pescado. Varela, 1, $29-48$.

Oliveira Filho, P. R. C., Reis, P. V. M., Araújo, I. B., Raul, L. J., Shinohara, N. K. S., \& Daza, T. E. L. (2017). Avaliação de linguiças de tilápias do nilo (Oreochromis niloticus) submetidas a diferentes métodos de defumação. B. CEPPA, 35(2), 1-14.

Ordoñez Pereda, J. A.; Rodriguez, M. I. C.; Alvarez, L. F.; Sanz, M. L. G.; Minguillón, G. D. G. F. (2005). Tecnologia de alimentos -Alimentos de origem animal. Artmed, 2, 279p.

Pereira, S. A., Shitsuka, D. M., Parreira, F. J. \& Shitsuka, R. (2018). Metodologia da pesquisa científica. UFSM.

Ribeiro, S. C. A. Secagem e defumação líquida de filé de peixe Matrinchã (Brycon cephalus). (2000). Dissertação (Mestrado em Engenharia de Alimentos) Universidade Estadual de Campinas.

Sa Vieira, P. H. S., Melo, C. C., Medeiros, R. F., Vasconcelos-Filho, M. B., Moura, J. V. S., Albuquerque, C. A., \& Oliveira-Filho, P. R. C. (2015). Produtos de valor agregado de tilápia (Oreochromis niloticus) utilizando diferentes concentrações de amido. Acta of Fisheries and Aquatic Resources, 3 (1), $41-53$.

SAS Institute (Cary, USA). (2010). SAS/STAT Users guide, version6. (4a ed.), Cary. 943. 
Research, Society and Development, v. 10, n. 11, e341101119728, 2021

(CC BY 4.0) | ISSN 2525-3409 | DOI: http://dx.doi.org/10.33448/rsd-v10i11.19728

Sidonio, L., CavalcantI, I., Capanema, L., Morch, R., Magalhães, G., Lima, J., Burns, V., Júnior, A. J. A., \& Mungioli, R. (2012). Panorama da aquicultura no Brasil: desafios e oportunidades. Agroindústria, BNDES Setorial 35, $421-463$.

Sigurgisladottir, S., Sigurdardottir, M. S., Torrissen, O., Vallet, J. L., \& Hafsteinsson, H. (2000). Effects of different salting and smoking processes on the microstructure, the texture and yield of Atlantic salmon (Salmo salar) fillets. Food Research International, 33(10), 847-855.

Silva, D. J. \& Queiroz, A. C. (2002). Análise De Alimentos: Métodos Químicos e Biológicos. (3a ed.), Universidade Federal de Viçosa, p. $235,2002$.

Siqueira, A. A. C. Z. (2001). Efeitos da irradiação e refrigeração na qualidade e no valor nutritivo da tilápia (Oreochromis niloticus). 137f. Tese (Mestrado) Escola Superior de Agricultura Luiz de Queiroz, Piracicaba, 2001.

Sleder, F. (2015). Desenvolvimento e caracterização de linguiça frescal de Tambaqui (Colossoma macropomum). Dissertação (Mestrado em em Ciência Animal) - Universidade Federal de Mato Grosso. Cuiabá.

Souza, M. L. R. D., Baccarin, A. E., Viegas, E. M. M., \& Kronka, S. D. N. (2004). Defumação da tilápia do Nilo (Oreochromis niloticus) inteira eviscerada e filé: aspectos referentes às características organolépticas, composição centesimal e perdas ocorridas no processamento. Revista Brasileira de Zootecnia, 33, 27-36.

Souza, M. L. R. D. (2002). Comparação de seis métodos de filetagem, em relação ao rendimento de filé e de subprodutos do processamento da Tilápia-do-Nilo (Oreochromis niloticus). Revista Brasileira de Zootecnia, 31, 1076-1084.

Souza, I. J. A., Kischnik, P. G., \& Lima, L. K. F. (2016). Desenvolvimento e Avaliação de Linguiça de Pescado Elaborado com Carne de Pirarucu. In Embrapa Pesca e Aquicultura-Artigo em anais de congresso, Palmas. Anais. Palmas: Ubec,

Souza, M. L. R. de, Silva, D. D. S. da, Pereira, I. L., Rocha, L. M. P., Oliveira, G. G., Coradini, M. F., Matiucci, M. A., Feihrmann, A. C., \& Goes, E. S. dos R. (2021a). Inclusion levels of flour made from smoked Nile tilapia trimmings in extruded corn snacks. Research, Society and Development, 10(8), e33410817243.

Souza, M. L. R., Souza, E. D., Matiucci, M. A., Feihrmann, A. C., Oliveira, G. G., Sbaraini, S. C., Santos, S. M., Santos, F. V., Goes, M. D., \& Goes, E. S. R. (2021). Inclusão de toucinho em kaftas elaboradas com aparas de filés de tilápia: composição química, microbiológica e sensorial. Ciência e Tecnologia de Alimentos. Editora científica. 386-400.

Torres, E. A. F. S., Campos, N. C., Duarte, M., Garbelotti, M. L., Philippi, S. T., \& Minazzi-Rodrigues, R. S. (2000).

Proximate food composition and caloric value of foods from animal origen. Journal of Food Science and Technology, 20(2).

Vasiliadou, S., Ambrosiadis, I., Vareltzis, K., Fletouris, D., \& Gavriilidou, I. (2005). Effect of smoking on quality parameters of farmed gilthead sea bream (Sparus aurata L.) and sensory attributes of the smoked product. European Food Research and Technology, 221(3), 232-236.

Vaz, S. K. (2005). Elaboraçăo e caracterizaçăo de linguiça frescal tipo toscana de tilápia (Oreochromis niloticus). Dissertação (Mestrado em Tecnologia do Alimento) - Universidade Federal do Paraná. Curitiba, 2005.

Verdi, R., \& Souza, M. L. R. (2015). Inclusão de mix desidratado de peixe em linguiça defumada e quibe de peixe. In: Encontro Anual de Iniciação Científica, 24. Londrina. Anais Londrina: EAIC UEL. 